\title{
The Covid-19 pandemic and gendered division of paid work, domestic chores and leisure: evidence from India's first wave
}

\section{Ashwini Deshpande ${ }^{1}[$}

Received: 1 February 2021 / Accepted: 22 June 2021 / Published online: 18 July 2021

(c) Springer Nature Switzerland AG 2021

\begin{abstract}
Examining high frequency national-level panel data from Centre for Monitoring Indian Economy (CMIE) on paid work (employment) and unpaid work (time spent on domestic work), this paper examines the effects of the first wave of the Covid19 pandemic on the gender gaps in paid and unpaid work until December 2020, using difference-in-differences (D-I-D) for estimating the before (the pandemic) and after (the pandemic set in) effects, and event study estimates around the strict national lockdown in April 2020. The DID estimates reveal a lowering of the gender gap in employment probabilities which occurs due to the lower probability of male employment, rather than an increase in female employment. The first month of the national lockdown, April 2020, saw a large contraction in employment for both men and women, where more men lost jobs in absolute terms. Between April and August 2020 male employment recovered steadily as the economy unlocked. The event study estimates show that in August 2020, for women, the likelihood of being employed was 9\% points lower than that for men, compared to April 2019, conditional on previous employment. However, by December 2020, gender gaps in employment were at the December 2019 levels. The burden of domestic chores worsened for women under the pandemic. Men spent more time on housework in April 2020 relative to December 2019, but by December 2020, the average male hours had declined to below the pre-pandemic levels, whereas women's average hours increased sharply. Time spent with friends fell sharply between December 2019 and April 2020, with a larger decline in the case of women. The hours spent with friends recovered in August 2020, to again decline by December 2020 to roughly one-third of the pre-pandemic levels. The paper adopts an intersectional lens to examine how these trends vary by social group identity.
\end{abstract}

Keywords Covid-19 $\cdot$ Lockdown · Employment $\cdot$ Gender $\cdot$ Time use $\cdot$ India

Ashwini Deshpande

ashwini.deshpande@ashoka.edu.in

1 Department of Economics, Ashoka University, Plot No. 2, Rajiv Gandhi Education City, National Capital Region, P.O.Rai, Sonipat, Haryana 131029, India 
JEL Classification J1 J6 $\cdot \mathrm{O} 53$

\section{Motivation}

Contrary to global and historical trends, Indian female labour force participation has remained persistently low over decades, and has declined precipitously over the last 15 years, despite the presence of factors necessary for its rise, viz., rising female education and lower fertility. The low level as well as the decline have been extensively studied; both are artefacts of a combination of factors-(mis)measurement, supply-side and demand-side issues (Deshpande \& Kabeer, 2019). Historically, large demographic shocks have contributed to shifts in established gendered labour market norms. For instance, evidence suggests that the 1918 Spanish Flu epidemic in India led to a temporary increase in female labour force participation in 1921, believed to have been driven by distress labour supply by widows and rising wages (Fenske et al., 2020). Therefore, a question worth investigating is whether the first 8 months of the Covid-19 pandemic, which in its first month (April 2020) saw a sharp drop in employment with fluctuating recovery thereafter, result in changes in gender gaps in employment and labour force participation in India; and if yes, what the specific contours of these shifts were.

Early national-level estimates revealed that in the first month of the stringent nation-wide lockdown in April 2020, in absolute numbers more men lost employment than women (104 million and 17 million respectively). However, conditional on being employed pre-lockdown, women were roughly $20 \%$ points less likely to be employed in April 2020 (Deshpande, 2020b). Desai et al. (2020)'s results, based on a survey in the Delhi Metropolitan Area, are similar in direction, in that the absolute loss of employment was greater for men compared to women. Kesar et al. (2020), based on phone survey data in selected states till May, find that women, especially rural women, were more likely to lose employment compared to men. Chiplunkar et al. (2020), using job postings on another employment portal (Shine.com) find a dramatic contraction in hiring in the first months of the pandemic, especially for young, less educated and female job seekers. They find that advertisers post fewer jobs in female dominated occupations.

While the early evidence from the lockdown did not suggest any major shifts in the gender gaps in the labour market, did this pattern change with the steady unlocking of the economy? A study released by LinkedIn, based on their internal data for India, found an increase of $7 \%$ points in women's participation in the labour force between April and July, 2020. ${ }^{1}$ Their argument is that normalisation of work-fromhome (WFH) and flexible hours has allowed women to enter the workforce.

An important dimension that negatively affects women's labour force participation is their predominant responsibility to get housework and domestic chores done. Across the world, women spend more time on domestic chores and care work than

\footnotetext{
${ }^{1}$ https://www.livemint.com/news/india/work-from-home-boosted-gender-parity-in-india-s-says-linkedinreport-11601361523068.html.
} 
men. India has amongst the most unequal gender division of household work globally. Early evidence indicated that the gender gap in average hours spent on domestic work hours decreased in the first month of the lockdown due to an increase in the male distribution of hours (Deshpande, 2020b). Was this shift a very short-lived blip or has this decline in the gender gap persisted beyond the first month? If it is the latter, in principle, it could set the stage for a rise in female labour supply, as suggested by the LinkedIn report. Of course, whether female employment actually increases is a function of several other factors, including demand for female labour and adequate employment opportunities.

The Covid-19 pandemic, due to its emphasis on social distancing as a key element in slowing the transmission of the disease has increased isolation and stress, which is compounded by economic and disease-related anxieties. ${ }^{2}$ In this scenario, time spent with friends could act as a stress-buster and provide the much-needed emotional support. There is no quantitative data on mental health; I examine the gendered nature of the change in time spent with friends during the pandemic and how this has changed with lockdown and unlockdown of the economy as suggestive of the gendered impact of the pandemic on well-being.

Using nationally representative, high-frequency panel data, this paper examines the evidence from India on the impact of the Covid-19 pandemic on the gendered division of paid work (employment), unpaid work (time spent on domestic work) and time spent with friends. The evidence from India contributes to the rapidly emerging literature on the impact of Covid-19 on inter-group inequalities across the world. If the pandemic did, in fact, manage to shift the needle on sticky gender norms in paid and unpaid work, it would be massive silver lining to the dark phase of the pandemic and economic contraction. Any such shift in India has significant implications for livelihoods and quality of life of a third of the world's population. India has been struggling with slowing growth, rising inequality and significant persistent gender gaps and if the pandemic enables the economy to break out of persistent patterns, this would be much-needed and welcome development.

\subsection{Global evidence and related literature}

Global evidence indicates that the slowdown and stoppage of economic activity due to the Covid-19 pandemic is disproportionately hurting women. According to the latest figures released by the US labour bureau, large numbers of women in the US are dropping out of the labour force altogether. The number of women aged 20 years or older in the labour force (including employed and unemployed women) declined by 865,000 between August and September 2020, compared to a corresponding decline of 216,000 men. There were 2.4 million fewer women in the labour force in September 2020 compared to exactly one year earlier (September 2019), compared to roughly 1.5 million fewer men. ${ }^{3}$ This pattern is confirmed by research studies

\footnotetext{
${ }^{2}$ https://www.cdc.gov/coronavirus/2019-ncov/daily-life-coping/managing-stress-anxiety.html.

${ }^{3}$ https://www.bls.gov/news.release/empsit.t01.htm.
} 
from various parts of the world which demonstrate that the first-order employment effects are more adverse for women than men [Alan et al. (2020) for the US; Andrew et al. (2020) for the UK, Farre et al. (2020) for Spain, Ilkkaracan and Emel (2020) for Turkey among others].

The impact of recessions on job losses is gendered, but not necessarily in one direction. ${ }^{4}$ For instance, earlier recessions in the USA (2008-2009) resulted in more job losses for men than women. However, this time around, women are more likely to bear the brunt because of the nature of businesses facing extended closure or possibly the threat of permanent closure (Alan et al., 2020). Restaurants, hotels, large retail spaces like malls and department stores, entertainment centres on one end, and domestic workers like maids, nannies, cleaners etc., on the other end of the workspace are large-scale employers of women.

A review of the evidence from other countries during earlier epidemics $(\mathrm{H} 1 \mathrm{~N} 1$, Ebola) reveals that increased domestic responsibilities, e.g. due to school closures, had differential effects on men and women. As their childcare burden increased, women's labour force participation fell, either in the form of reduced hours or withdrawal from paid labour altogether (Deshpande 2020a). In the US, evidence suggests that mothers are facing a harsh dilemma due to school closures, summed up by the title of a New York Times article: "In the Covid-19 Economy, You Can Have a Kid or a Job. You Can't Have Both."5

As Indian women's participation in paid work is already severely constrained by unpaid work, which includes care work and domestic chores, this paper investigates how this pattern has shifted if at all. The LinkedIn India report suggests that Indian women were able to increase work participation despite school and childcare facilities being closed, due to the presence of domestic help and live-in grandparents, in addition to flexible hours and the ability to work remotely, which presumably allowed them to combine care responsibility with demands of paid work. Does national-level macro data support this evidence?

\subsection{Main results}

The analysis in this paper examines the gendered impact of Covid-19 induced lockdowns; additionally, it also adopts an intersectional lens to examine how changes in gender gaps vary by social identity. The main results are as follows. Following a sharp drop in employment in April 2020, employment recovered through May-August 2020 for both men and women, but started to decline thereafter. There is no evidence of an increase in female work participation over the 6 months of the pandemic over and above the recovery to near pre-pandemic levels.

Broken down by education levels, the post-August decline in female employment is driven the decline in employment of women with very low levels of education: primary and below and illiterate. The highly educated women suffered

\footnotetext{
${ }^{4}$ I have discussed this in Deshpande (2020a).

5 https://www.nytimes.com/2020/07/02/business/covid-economy-parents-kids-career-homeschooling. html action $=$ click\&module $=$ Top $\% 20$ Stories \&pgtype $=$ Homepage.
} 
the least in the job cuts in April, when overall employment plummeted, mean employment for this group of women declined between April and August 2020, i.e. during the recovery phase than during the contraction phase. However, between August and December 2020, the average employment is back to its prepandemic levels.

Examining changes in employment by social group, the largest decline in employment occurred for lowest ranked Scheduled Caste (SC) or Dalit men, followed by Scheduled Tribe (ST) men, then men belonging to the intermediate ranked Other Backward Classes (OBC). The so-called Upper Caste (UC) men registered the smallest decline in employment. This ranking or hierarchy of groups is socially prevalent; the use of the terms "lower" or "higher" does not reflect an endorsement of the caste hierarchy by the author.

Female employment in each social group is lower than male, but the gender gap is (a) narrowest for the ST group, and (b) shows a fair amount of month-to-month fluctuation. In terms of recovery, only UC men seem to have made a recovery by December 2020. Men and women across all other social groups have not exhibited a clear recovery in employment.

The D-I-D estimates, comparing pre-pandemic or "before" period (January 2019-March 2020) to the "after" period (April 2020- December 2020), show that male employment declined from 44 to $38 \%$ from the "before" to the "after" period, whereas female employment declined from 37 to $36 \%$. The gender gap in the probability of employment was $7 \%$ points in the pre-pandemic period. This declined significantly in the "after" period (April-December 2020) to $2 \%$ points. This decline is due to the lower probability of male employment, rather than due to an increase in the probability of female employment.

The event study estimates for the probability of employment show that accounting for lagged employment, the likelihood of women being employed in August 2020 was $9 \%$ points lower than that for men, compared to the pre-pandemic period (April 2019). By December 2020, the gender gaps in the probability of being employed were back to the pre-pandemic levels.

The gender gap in the average hours spent on domestic work registered a decline in the first month of the lockdown (April 2020) due to an increase in male hours. However, in August male hours had declined again, though not to the pre-pandemic levels. By December 2020, women's hours spent on domestic work had increased significantly and the male hours had declined below the pre-pandemic levels, thereby significantly worsening the gender gap. Examining caste differences in time spent on housework reveals that the spike in male hours on housework was due to an increase by Dalit men.

The time spent with friends declined sharply in April 2020 during the month of the strict lockdown. In August 2020, it recovered for both men and women, but was far below the pre-pandemic levels. By December 2020, there was once again a sharp decline to reach levels roughly one-third of the pre-pandemic period. While women spent more time with friends compared to men in the pre-pandemic months, this is no longer the case. Thus, the decline in time spent with friends has been greater for women. 
The rest of this paper is organised as follows. Section 2 examines the shifts in gender gaps in paid work. Section 3 discusses time spent on domestic work (unpaid work) and with friends. Section 4 contains a discussion of the main results and offers concluding comments.

\section{Paid work: employment}

\subsection{Data}

This paper uses data from the Centre for Monitoring Indian Economy (CMIE)'s Consumer Pyramids Household Survey (CPHS) as well as Income Pyramids member survey. ${ }^{6}$ I use six waves of the CPHS: Wave 16 (January-April 2019), Wave 17 (May-August 2019), Wave 18 (September-December 2019), Wave 19 (January-April 2020), Wave 20 (May-August, 2020) and Wave 21 (September-December, 2020). Since each household is surveyed three times per year, these 24 months allow up to six observations per person, subject to attrition. ${ }^{7}$ These data provide us with a pre- and post-pandemic panel of individuals, with 9 months in the post-pandemic period [ 1 month in Wave 19, viz., April 2020, and 8 months of Waves 20 and 21 (May-December 2020)], which allows us to track changes in the status of the same individuals over time.

The respondent is asked to list the employment status of all members of the household, including for household members for whom this question is not applicable, e.g. children or elderly members. If the question is applicable, the options for employment status are employed; not employed, but willing and looking for work; not employed but willing to work; and not employed, not willing and not looking for work. I have classified the latter as out of the labour force (OLF) and the middle two categories as "unemployed".

For all empirical results, I have created a panel of individuals who are observed in all the waves and for whom employment data are available. ${ }^{8}$

We should note that the CMIE employment and labour force participation figures for women are lower than those available from other widely used surveys such as the official National Sample Survey (NSS), or the publicly available India Human Development Survey (IHDS). ${ }^{9}$ Leaving aside the considerable issues related to the

\footnotetext{
${ }^{6}$ CMIE is a private data provider (with data available only to subscribers) collecting weekly data at the national level since January 2016. It is a longitudinal data set covering 174, 405 households (roughly 10,900 households per week, and 43,600 per month). Each household is followed three times per year.

7 There is some attrition, which is to be expected in panel data. Additionally, April 2020 was a particularly disruptive month for ongoing surveys due to the complete lockdown. The CMIE shifted to phone surveys successfully; they have described the process here: https://consumerpyramidsdx.cmie.com/kom$\mathrm{mon} / \mathrm{bin} / \mathrm{sr}$.php?kall=wkb.

8 The total numbers are not exactly matching due to missing observations on employment status.

9 The most recent round of the former are only available for 2018-2019, and for the latter for 20112012. Thus, the CMIE data are currently the only national-level source for assessing changes in employment in real time, especially if we want to assess the immediate effect of the national lockdown which started in the last week of March, 2020.
} 


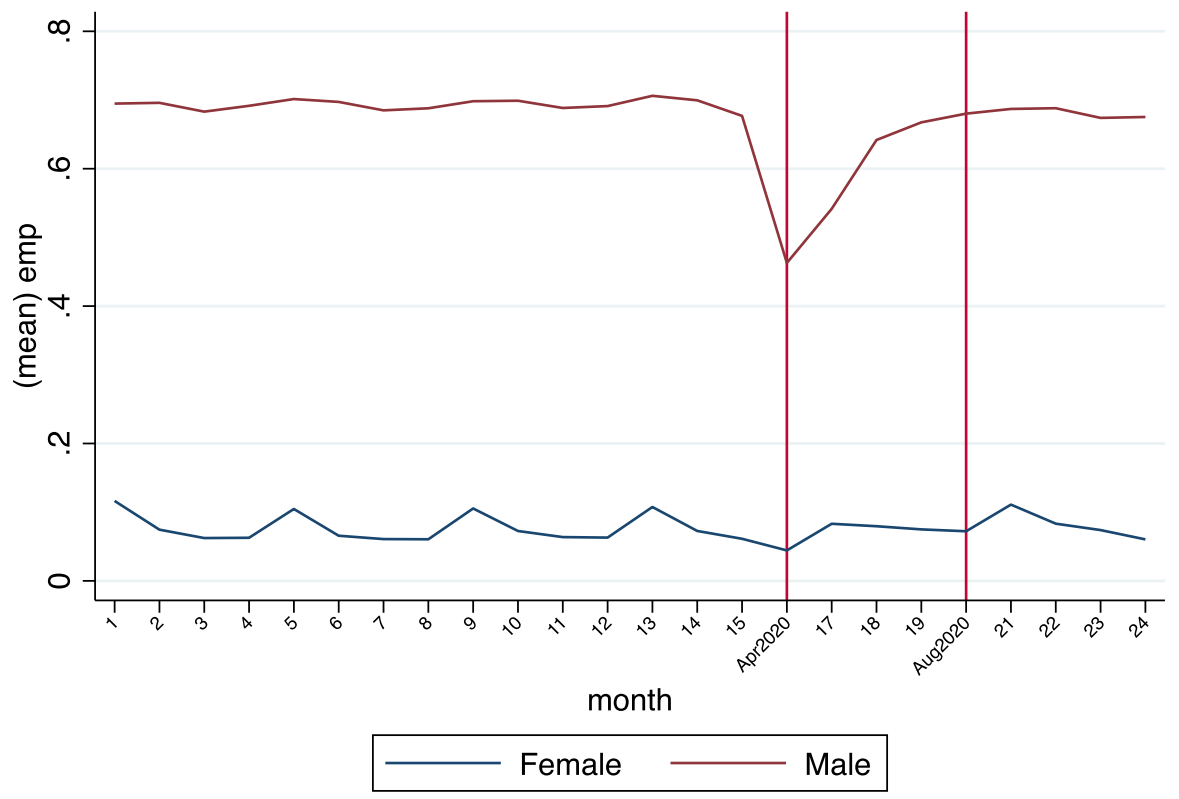

Fig. 1 Mean employment, by gender, Jan 2019-Dec 2020. Source: Author's calculation using CMIE unit-level data

(lack of) accurate measurement of women's work, the differences are attributable to definitions used by the various surveys. Very briefly, the CMIE rate is comparable to the the "current weekly status" (CWS) definition used by the NSS, and not the principal or usual status definition which measures the majority time in the year, or time spent in any 30-day period in employment. For CWS, a person is considered employed if the person has worked for at half a day in the past 7 days. CMIE takes the status as of the day of the interview and not the past 7 days. If a person is employed for $4 \mathrm{~h}$ or more on that day, she is considered employed. The CMIE definition is more stringent and therefore the estimates are lower than those obtained via the NSS. For the purpose of this paper, what matters is that the definition remains consistent over time, and we are able to measure increases or decreases accurately.

\subsection{Descriptive statistics}

Figure 1 shows the trend in average employment for men and during the 24 months between January 2019 and December 2020. We see a sharp dip in April 2020, followed by a recovery between April and August. After August, the recovery tapers off for men, with female employment registering a decline between August and December 2020. CMIE figures reveal that average employment from January to March 2020 (pre-pandemic) was 403 million, which declined to 282 million in April 2020. By August 2020, this had increased to 393 million. The comparative figures for men are 360, 256 and 353 million respectively, and for women are 43, 26 and 39 
million respectively. The male-female gaps in total employment are stark in both pre and post-pandemic periods. Prima facie, national level estimates do not support the evidence of a sharp increase in female employment, as suggested by the LinkedIn survey. If anything, these numbers suggest an increase in the urban male-female employment ratio from 9.04 in May 2020 to 10.58 in July 2020. For rural areas, the male-female employment ratio was 8.5 in August 2020, an increase from the prepandemic average of 7.91 .

The month-over-previous-month change in employment during 2020 based on CMIE data reveal the following. Given the pre-existing gender gaps in total employment, more men lost jobs in April, 2020, compared to women. The recovery in employment between May and August was also overwhelmingly male. In August 2020, fewer women were employed compared to July. Male employment increased in August, September and October (m-o-m basis), but the magnitude of increase was far lower compared to May and June. Female employment declined in October, November and December. In November and December, male employment declined compared to the previous month. ${ }^{10}$

Table 1 shows the key descriptive statistics across the six waves. Waves 1, 2 and 3 (January to December 2019) are fully in the "before" (pre-pandemic period), and Waves 5 and 6 (May-December 2020) are fully in the "after" period. Wave 4 has 5 weeks in the "after" period (last week of March when India went into full lockdown, followed by 4 weeks in April 2020). Wave 5 (May-August 2020) saw the economy unlock in varying degrees across the country. Wave 6 (September-December 2020) was marked by further unlocking. The wave-wise averages mask the monthly variations in key averages. The monthly averages for key variables can be accessed in a supplementary online file. ${ }^{11}$

Figure 2 shows the change in total employment by month and rural-urban sector. The initial drop in employment (between March and April 2020) was higher in urban areas (33\%) compared to rural (29\%), i.e. employment figures for April 2020 were 67 and $71 \%$ of the average employment during the preceding year (March 2019-2020), for urban and rural areas, respectively. This was to be expected because sectors that shut down completely included manufacturing and services, which are mostly urban based. Rural women's employment suffered the largest fall at $57 \%$ of the previous year's average. This ratio was $73 \%$ for rural men, $69 \%$ for urban women and $67 \%$ for urban men. The decline in female LFPRs since 2004-2005 has been driven by a decline in LFPRs of rural women. The pandemic-induced suspension of economic activity revealed a similar pattern.

In rural areas, total employment increased till September and declined thereafter. In urban India, the September-December decline is slightly less sharp compared to urban, and the December 2020 employment is roughly at the immediate pre-lockdown levels. Both rural and urban female employment has been declining since September, with a larger decline in the case of rural women.

\footnotetext{
${ }^{10}$ https://ceda.ashoka.edu.in/monthly-changes-in-employment-in-2020-sectoral-gender-and-occupationprofile/.

11 https://www.dropbox.com/s/yrd21uztudl3dov/Supplementary_summarymonth.xlsx?dl=0.
} 


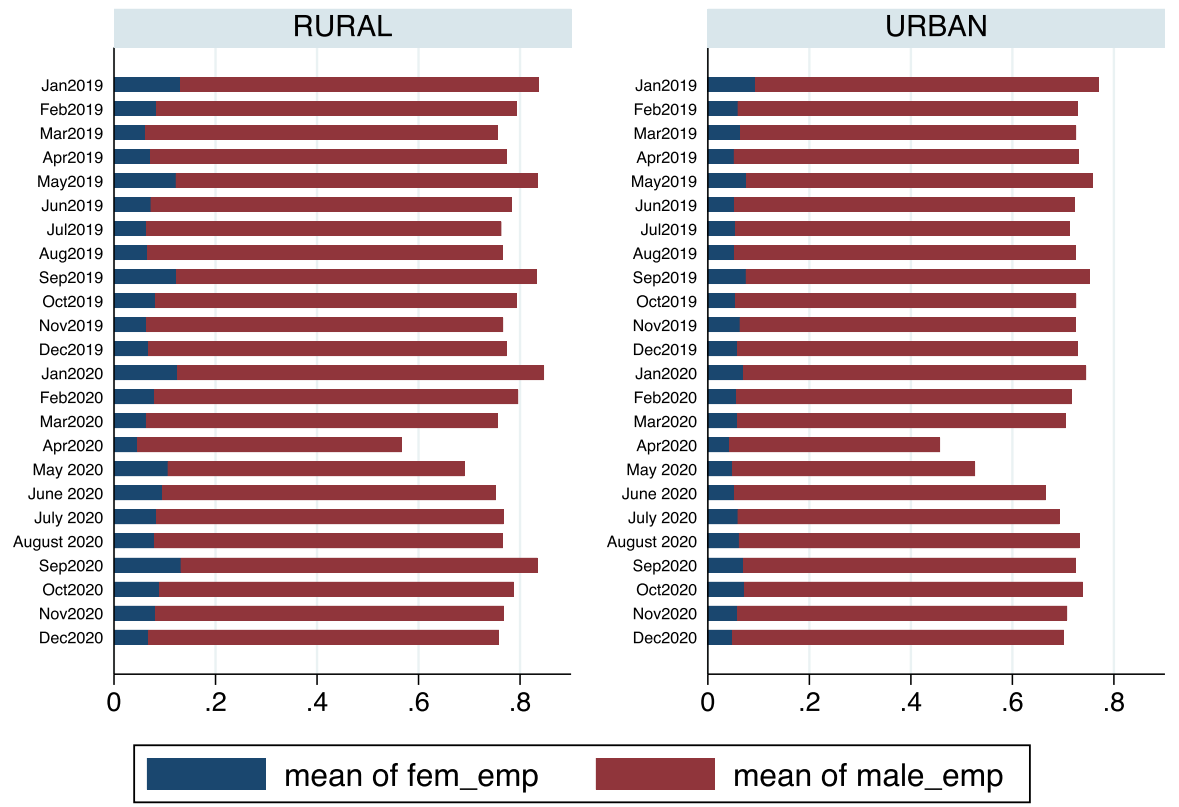

Fig. 2 Mean employment, by gender and sector, India. Source: Author's Calculation based on CMIE data

Thus, the immediate post-lockdown recovery in employment has not turned is not sustained.

\subsubsection{Industry and social group}

Table 1 shows how employment changed over the period across broad industry divisions separately for men and women. In agriculture and allied activities as well as in manufacturing, construction and processing, the decline in female employment in April was larger than male. By December 2020, in agriculture and allied activities, the levels of both male and female employment were back to the pre-pandemic levels.

In manufacturing, construction and processing, female employment recovered after April and fluctuated between September and December to reach a level lower than male. The overall fall in employment was steepest in the services sector, and male employment fell more than female in April. However, in subsequent months, male employment in the services sector has steadily risen, whereas female employment has fluctuated with a declining trend in the the last 3 months of 2020. In this sector, the gender gap in employment in December 2020 is larger than in the prepandemic period.

In the primary and home production sector, female employment declined sharply twice and more than male: in April as well as in July-August. The second decline was not accompanied by any decline in male employment, thereby leading to a gender gap. 


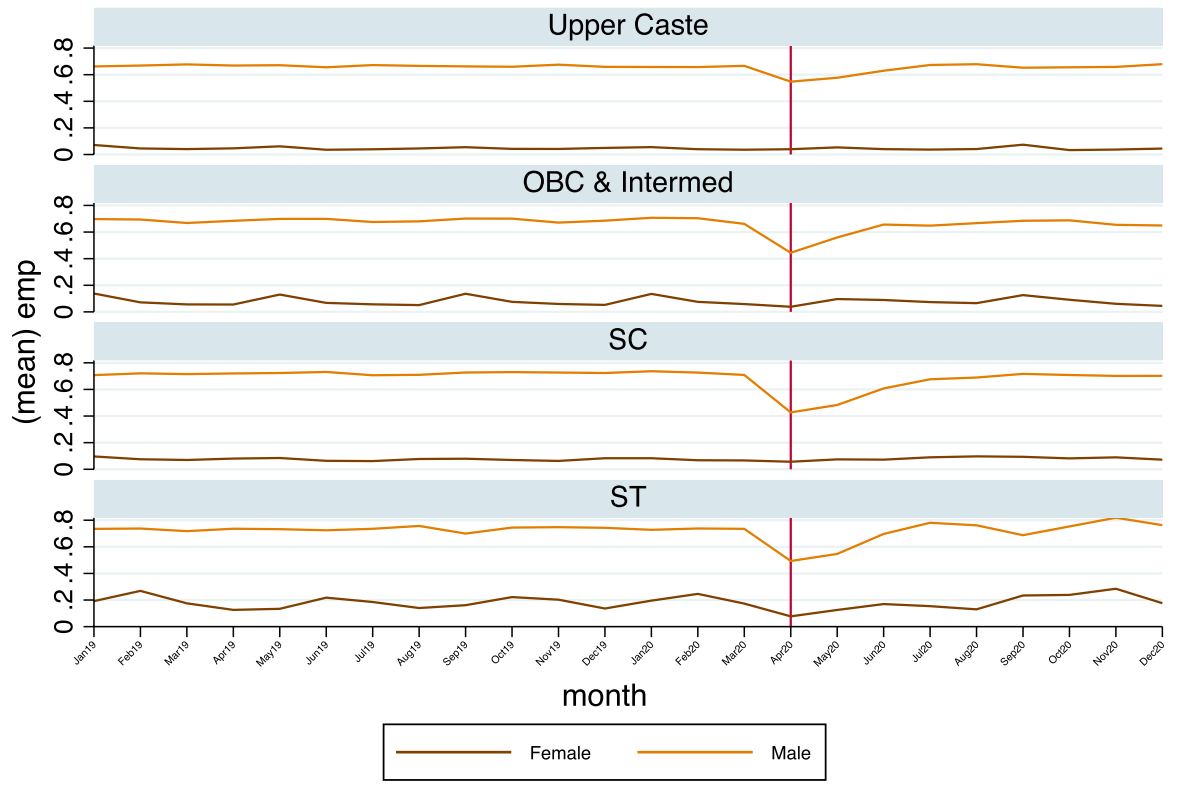

Graphs by caste

Fig. 3 Mean employment, by gender and caste, India

Economic outcomes in India are shaped crucially by social group identities such as caste and tribe, and there is evidence that the pandemic has not been neutral across social identities (Deshpande \& Ramachandran, 2020). The intersection of caste and gender reveals a more nuanced picture of which groups bore the brunt of the economic shock.

Figure 3 shows trends in employment across gender and social group based on the broad administrative categories of Scheduled Castes (SC), Scheduled Tribes (ST), Other Backward Classes (OBCs) and the residual, who can be seen as a proxy for upper castes (UC). Among the men, we see that the largest decline in employment occurred for SC or Dalit men, followed by Scheduled Tribe (ST), then OBC and finally, upper caste men registered the smallest decline in employment.

Female employment in each caste group is lower than male, but the gender gap is (a) narrowest for the ST group, and (b) shows a fair amount of month-to-month fluctuation. In terms of recovery, only UC men seem to have made a recovery by December 2020. All other men and women across all caste groups did not exhibit a clear recovery in employment.

\section{3 "Pre" and "Post" pandemic panel}

In order to examine the main effects of the pandemic, we begin by first focusing on the overall change between the months before the pandemic (January 2019-March 2020), and the months after the pandemic broke out at the national 


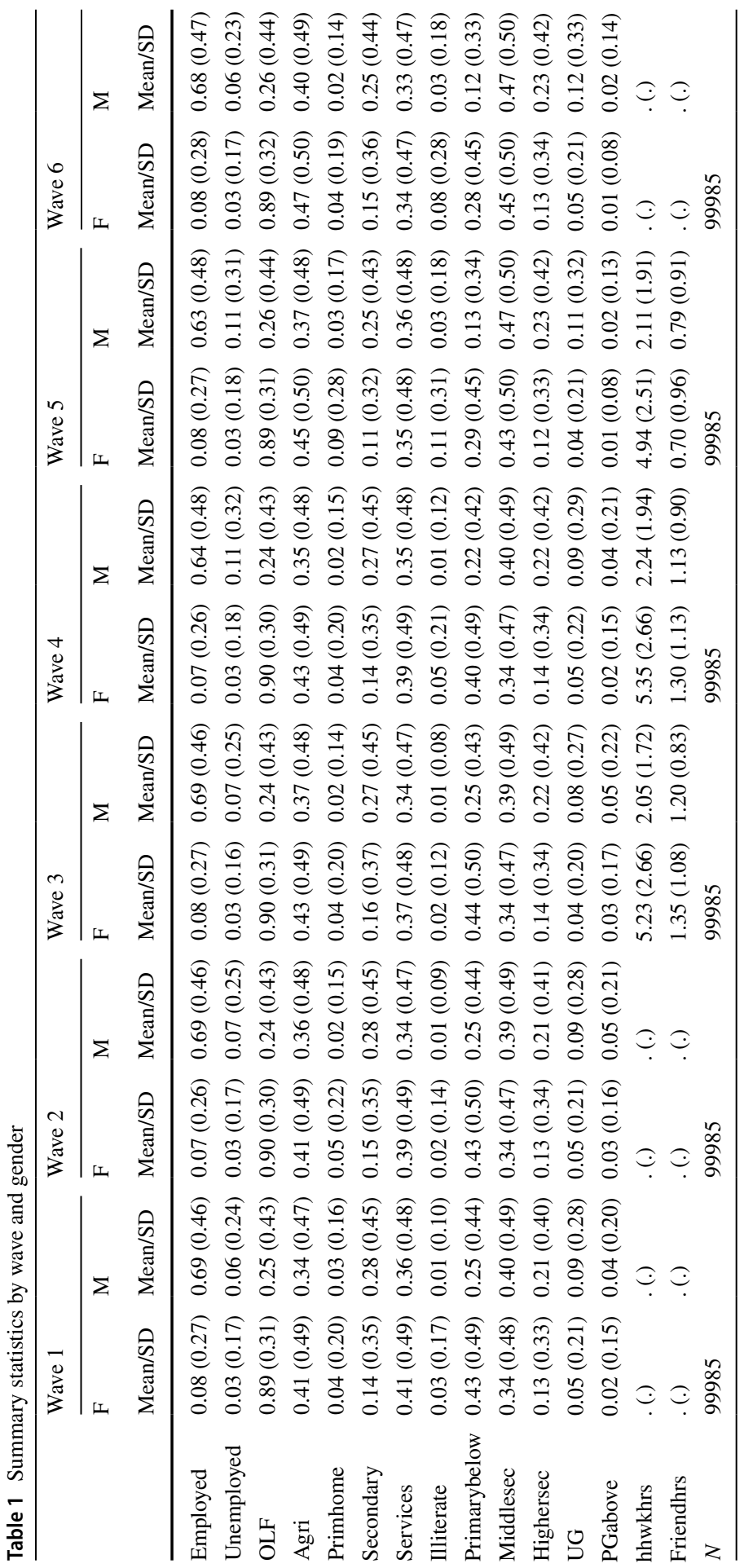


level (April-December 2020). We will call them "pre" and "post" respectively for brevity. India is in the second wave of the pandemic at the time of writing, thus the term post does not, by any means, imply that the pandemic is over. We can estimate a difference-in-differences (D-I-D) equation. Since this is panel data, each unit is observed before and after the event. Thus, the D-I-D estimation is not over individuals assigned to treatment and control groups. In our data, each individual is its own comparison. The first difference is estimated between two groups of individuals, men and women, and the second difference is a "convenient viewpoint" (Nichols, 2007 , p.512 12 , which in our case is the lockdown imposed to contain the outbreak of Covid-19.

$$
E m p_{i t}=\alpha+\beta \text { female }+\gamma p o s t+\delta \text { female } * \text { post }+i n d F E+\epsilon_{i}
$$

where $E m p_{i t}$ is a dummy for the employment status of individual $i$ in period $t$, which takes the value 1 if employed. female is the dummy variable for women. post is a binary variable that takes the value 1 for April 2020 onwards, and zero otherwise, and female $*$ post is the interaction term which gives the coefficients of interest, the D-I-D estimate of the effect of the pandemic on women's employment relative to men. This is estimated with individual fixed effects, with standard errors clustered at the district level for all individuals 15 years and older.

We estimate the same equation adding interactions, first with sector (rural/urban residence), and then with education levels. Equation (2) shows the interactions with education level (edlow), which is a binary variable taking the value 1 for those with upto 10 years of education and 0 for those with education level greater than 10 years.

$$
\begin{aligned}
\text { Emp }_{i t}= & \alpha+\text { Bfemale }+\gamma \text { post }+\theta \text { edlow }+\delta \text { female } * \text { post } \\
& +\zeta \text { female } * \text { post } * \text { edlevel }+ \text { indFE }+\epsilon_{i}
\end{aligned}
$$

Here $\zeta$ is the coefficient of interest, which gives us the D-I-D estimate of the differential effect of the pandemic on the employment probability of men and women by their education levels. It allows us to see if the effect of the pandemic varied by low versus high education level.

Figure 4 shows the marginal effect of the pandemic, separately for men and women, based on estimates from Eq. (1) in Panel A, and from Eq. (2) for edlevel in Panel $\mathrm{B}^{13}$. For ease of interpretation, Panel $\mathrm{B}$ shows the marginal effects in two smaller sub graphs, one for each level of education.

Panel A of Fig. 4 reveals that male employment declined from 44 to $38 \%$ from "pre" to "post", whereas female employment declined from 37 to $36 \%$. The gender gap in the probability of employment was $7 \%$ points in the pre-pandemic period. This declined significantly in the post pandemic period (April-December 2020) to $2 \%$ points. However, we should note that this decline is due to the lower probability

\footnotetext{
12 https://journals.sagepub.com/doi/pdf/10.1177/1536867X0800700403.

13 The results by sector are similar to that for the whole sample, i.e. the change between pre- and postpandemic between male and female employment do not vary significantly by sector, hence not being reproduced here.
} 

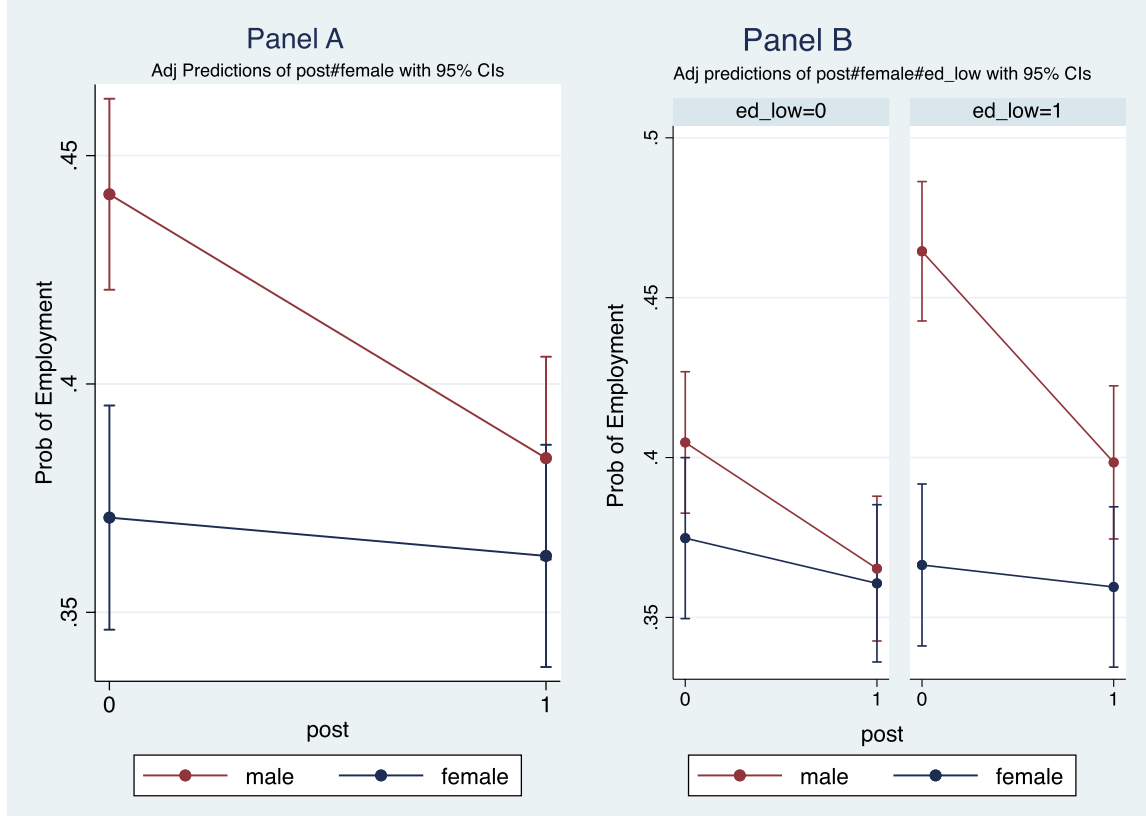

Fig. 4 Change in employment by gender, post-pandemic, India. Figure presents the marginal effects of the pandemic from the estimation of Eq. (1) $\mathrm{N}=599,910$. A Shows the estimation over the whole panel; B shows the results of interaction with two education levels, low and high

of male employment, rather than due to an increase in the probability of female employment.

Panel B of Fig. 4 reveals that male employment declined in both categories of education, but was sharper for men with lower levels of education (i.e. less than 10 years). For this category of men, the probability declined from 46 to $39.8 \%$, whereas for men with higher education levels, it declined from 40.4 to $36.5 \%$. Thus, despite overall recovery in employment, the effect of the pandemic has been to significantly lower the employment probability of men with lower education levels.

A binary division of the entire time period between "before" and "after" is useful to see the larger picture, but given the month-by-month changes in employment (Fig. 1), it is worth investigating changes over shorter intervals to understand the contours of the shifts in paid and unpaid work. Also, the strongest determinant of employment in any one period is lagged employment (employment in the previous period). With only two periods (pre and post), we are not able to introduce lags, but an analysis over shorter time intervals allows us to estimate a dynamic lagged model, as Sect. proceeds to do. 


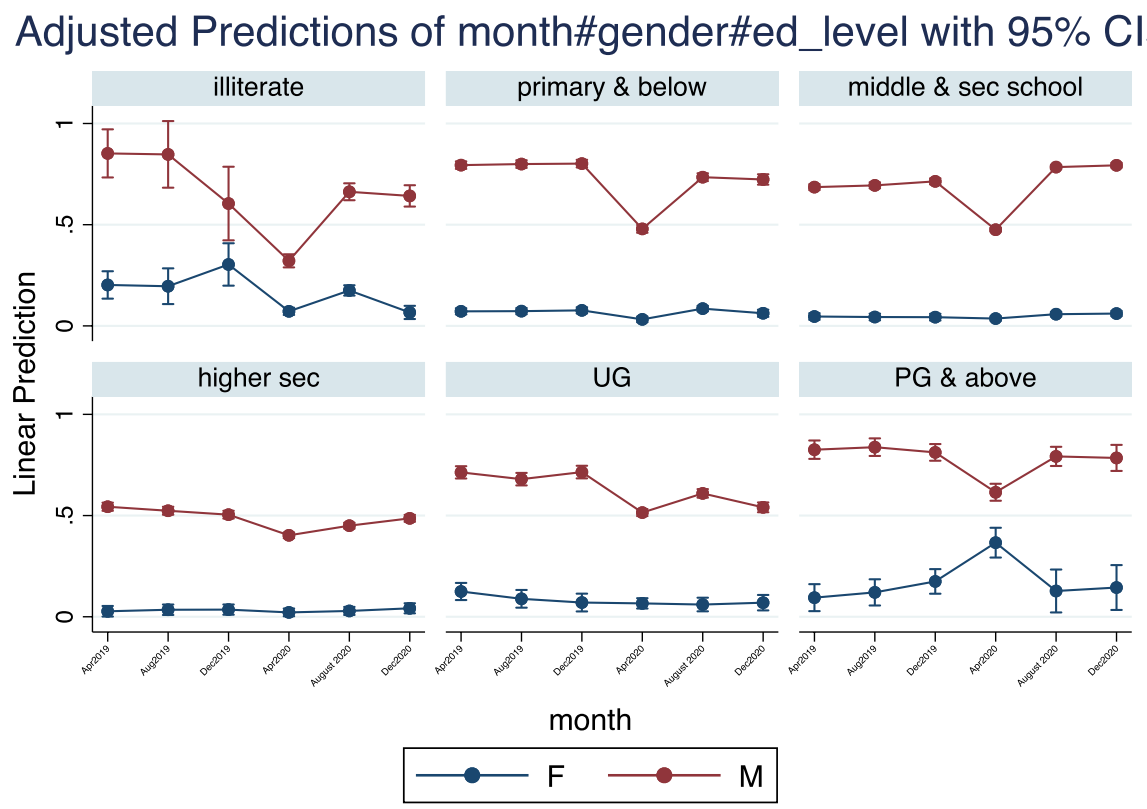

Fig. 5 Change in Mean Employment by Gender and Edu Level, 15 yrs \& older, India

\subsection{The lockdown panel}

Figure 1 demonstrates that the largest contraction in employment happened in 1 month, viz., April 2020, which was the month of the strictest lockdown. We can define a "lockdown panel" of individuals surveyed in April 2020 and compare their outcomes in the pre-pandemic period as well as during the "unlockdown" or the recovery phase. Most of the April 2020 respondents were interviewed in April 2019 in Wave 1; August 2019 in Wave 2; December 2019 in Wave 3; August 2020 in Wave 5 and December 2020 in Wave 6. Examining the changes in employment status for this panel of individuals will allow us to explore the full impact of the the lockdown and subsequent recovery.

\subsubsection{Education and employment}

Figure 5 plots the marginal effects for the probability of employment for the lockdown panel by gender and educational attainment following a three-way analysis of variance (ANOVA) estimation. ${ }^{14}$ For each education level, in all months for the lockdown panel, the probability of male employment is higher than that for female. Men in all educational categories registered a fall in probability of employment in April 2020, with fluctuating recovery in subsequent months. Consistent with the

\footnotetext{
14 This follows from a linear regression of employment on the interaction between month, gender and education level.
} 
larger picture presented in Fig. 5, we see that the drop in male employment was sharpest for illiterate men (from 85 to 32\% between April 2019 and April 2020), and the recovery in December 2020 (at 64\%) is below the pre-pandemic levels. UG men have also seen a trend decline in employment from $71 \%$ in December 2019 to $54 \%$ in December 2020.

Female employment pattern differs from male in one noteworthy dimension. In April 2020, highly educated women (PG and above) not only did not suffer job losses, on the contrary, their probability of employment increased from $17 \%$ in December 2019 to $36 \%$ in April 2020. This was the only category of workers that registered an increase in the probability of employment during lockdown. But as the economy unlocked, May and August 2020, as workers in all other educational categories registered an increase in employment, this category of women registered a decline in the probability of employment to $12.7 \%$ in August 2020, which increased to $14.5 \%$ in December 2020.

\subsection{Event study estimates: the lockdown panel}

This section runs regressions similar to Eqs. (1) and (2), but on the lockdown panel, i.e. individuals who are observed in April 2020. The time variable is "month", instead of "pre" and "post". Variables such as employment, wages, earnings are strongly path dependent, in that the likelihood of being employed in any period is strongly associated with employment in the previous period. Thus, the question that arises is whether we should run a time invariant fixed effects model (as in Eq. (1)) or a lagged-dependent variables model, i.e. do a dynamic panel data estimation. Angrist and Pischke (2009) highlight the dilemma of choosing between the two models, as including both fixed effects and lagged dependent variables introduce a bias, and estimating a time invariant fixed effects model will not estimate the true effect of time varying trends, viz., past employment. Given that the two models are not nested, one cannot estimate one and treat the other as a special case.

Angrist and Pischke (2009) show that using fixed effects when lagged-dependent variables matter will produce a treatment effect that is "too big". On the other hand, using a lagged-dependent dynamic panel data model will produce a treatment effect which will be "too small", as individual fixed effects will not be controlled. Thus, one option is to estimate both models and take the estimates as bounding the causal estimate we are trying to estimate (p. 184).

Accordingly, we estimate a fixed effects model, as in Eq. (1) above, on the lockdown panel, with month dummies capturing the time trends, instead of a binary pre/ post time dummy. This makes it an event study design. For the dynamic panel estimation with lagged dependent variable, we estimate Eq. (3) to get the event study estimates to account for the effect of being previously employed. By including a one-period lag, we lose 1 month of observations.

$$
E m p_{i t}=\alpha+\beta . \text { female }+\gamma . \text { month }+\delta . \text { female } * \text { month }+\phi . E m p_{i t-1}+\epsilon_{i}
$$

where $E m p_{i t-1}$ is the lagged employment and all other terms are the same as in Eq. ((1)). $\delta$ is the DID coefficient of interest. This does not include time invariant 

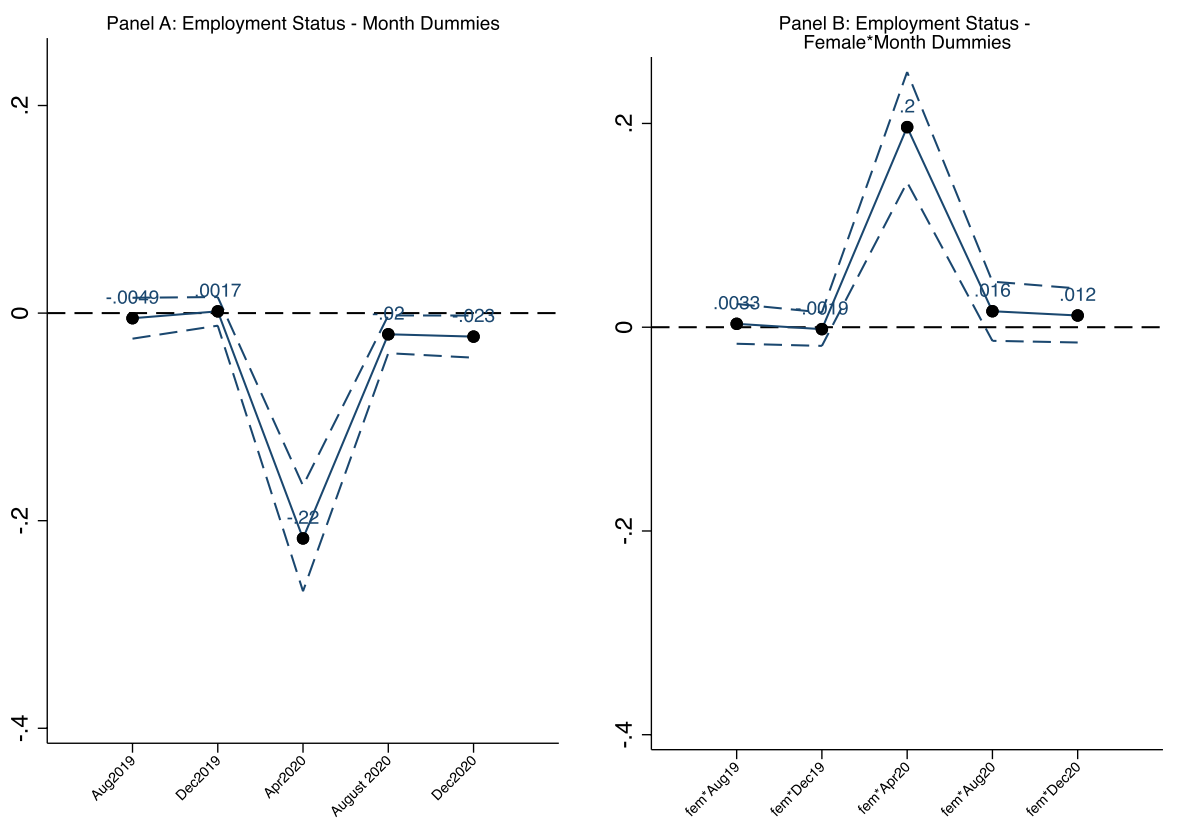

Fig. 6 Event study estimates for lockdown panel: fixed effects model. This figure plots the event study estimates by month arising from estimating Eq. (1) on the Lockdown Panel. The dependent variable is a dummy for being employed in period t. $N=91,428$. Intercept $=0.51$. The omitted month is April 2019. The dashed lines show the $95 \%$ confidence interval

individual fixed effects. We include district fixed effects and standard errors are clustered at the state level.

The results are shown in Figs. 6 and 7 respectively. Table 2 shows both estimates. Figure 6 with individual fixed effects shows that there was no significant change in the likelihood of being employed in August and December 2019 compared to April 2019. Post-pandemic, in April 2020, for men employment dropped by $22 \%$ points compared to April 2019. By December 2020, male employment was 2.3\% points lower than in April 2019.

The male female gaps did not change in the pre-pandemic months of August and December 2019. In April 2020, the gender gap in the likelihood of being employed reduced by $2 \%$ points. By December 2020 , the gap was back to the pre-pandemic level.

The results of the dynamic panel data model can be seen in Fig. 7, based on estimating Eq. ((3)). Accounting for lagged employment, we see that the drop in employment in April 2020 is 24\% points (compared to August 2019, since April 2019 gets omitted. However, we know from Fig. 5 that the likelihood of being employed in August 2019 is the same as in April). By August 2020, accounting for lagged employment, the likelihood of men being employed is $11 \%$ points higher than the pre-pandemic period. For women, after a $22 \%$ point convergence in April 2020, the likelihood of being employed in August 2020 is 9.5\% points lower than 

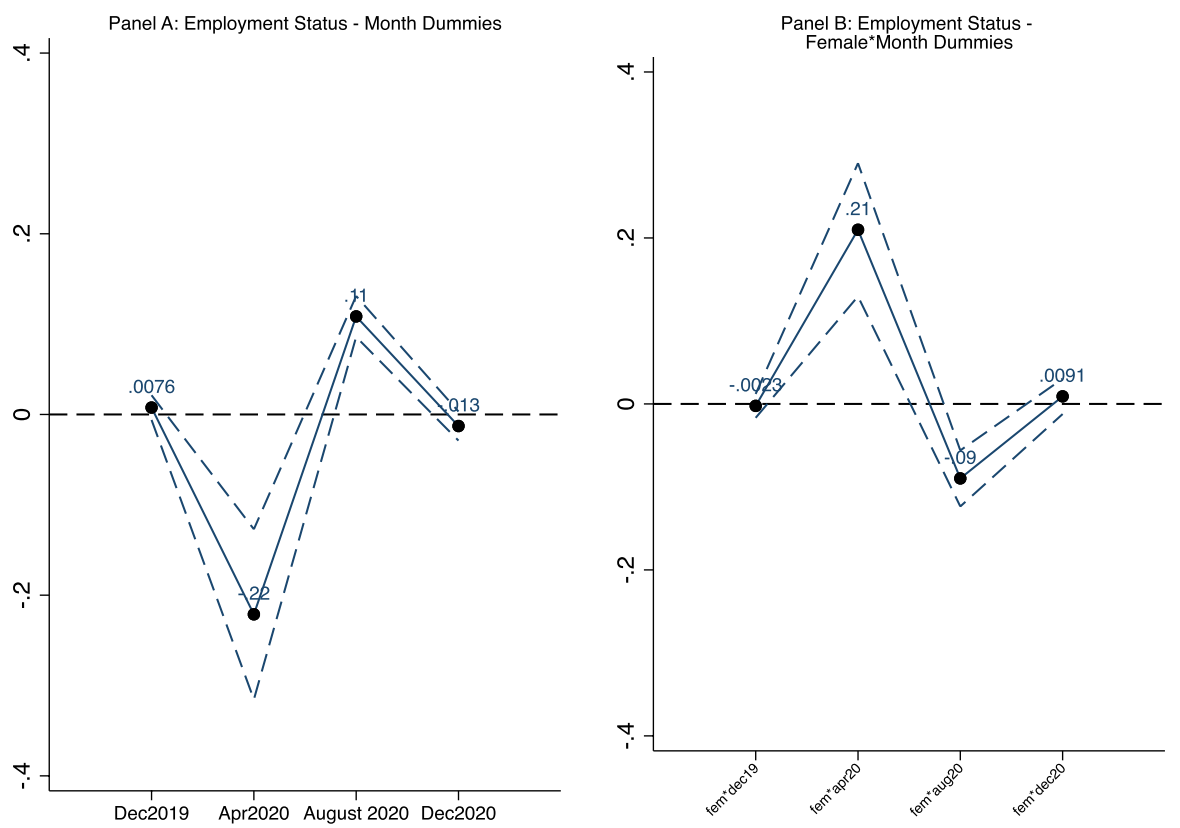

Fig. 7 Event study estimates for lockdown panel: dynamic panel data model. This figure plots the event study estimates for the lockdown panel arising from estimating Eq. (3). The dependent variable is a dummy for being employed in period t. $\mathrm{N}=76,190$. Intercept $=1.01$. The omitted month is August 2019. The first month, April 2019, drops out because of the inclusion of lags. The dashed lines show the $95 \%$ confidence interval

that for men. This indicates that the gender gap in the likelihood of being employed has widened relative to the pre-pandemic level.

It is important to note that the decline in the gender gap is due to the decline in male employment, rather than an increase in female employment, as we had noted in Fig. 2. Figure 8 shows that more clearly as it plots the marginal effects from the female * month interactions for each month. We see that in August 2020, the gender gap in employment had increased, whereas in December 2020 it is back to the prepandemic level (as the estimates in Fig. 7 show), but this is due to a decline in the probability of male employment, rather than an increase in female employment.

For those with desk jobs, work during lockdown shifted from the workplace into the home. A key dimension of "Work from Home" (WFH) is having to juggle multiple demands. Andrew et al. (2020), using data for England, are able to examine the quality of time at work, which is critical for productivity and learning. As the authors emphasise, this could impact future earnings and career progression. They find that mothers and fathers doing paid work used to be interrupted during the same proportion of their work hours before the crisis; after the crisis, mothers are interrupted over 50\% more often. These data are not available for India, and hence we cannot examine this question, but it is an important gender difference that is likely to be present in several contexts outside England, quite possibly in India. 


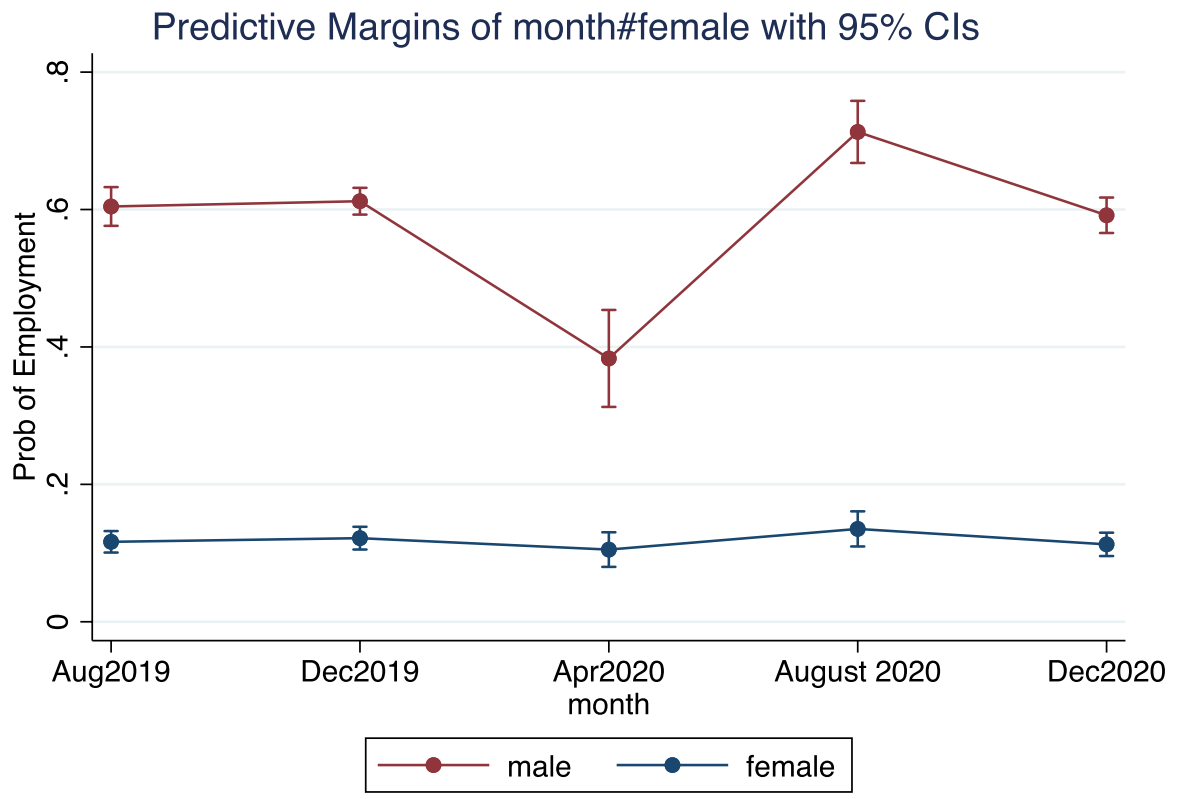

Fig. 8 Marginal effects, event study estimation with lagged emp, lockdown panel. This figure plots the marginal effects of month*gender from the event study estimates for the lockdown panel arising from estimating Eq. (3). The dependent variable is a dummy for being employed in period $\mathrm{t}$. $\mathrm{N}=76,190$. The omitted month is August 2019. The first month, April 2019, drops out because of the inclusion of lags.

\section{Adjusted Predictions of month\#gender with $95 \% \mathrm{Cls}$}

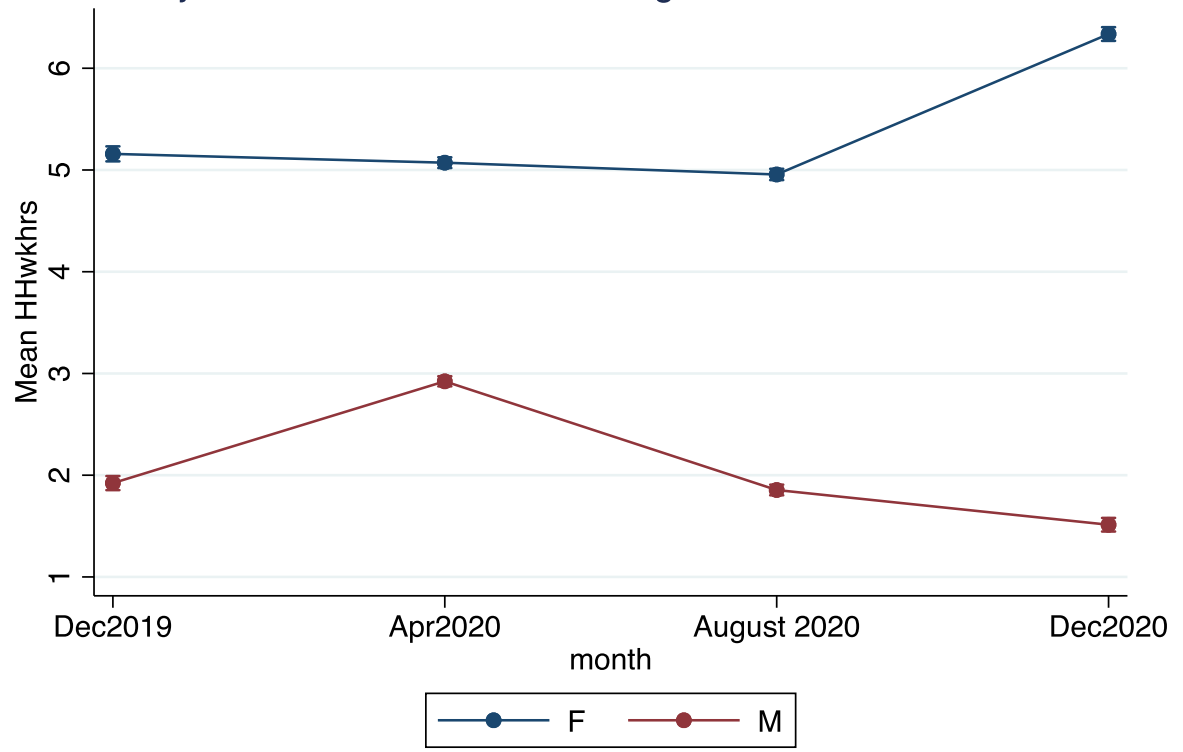

Fig. 9 Average hours spent on housework, by gender, India 


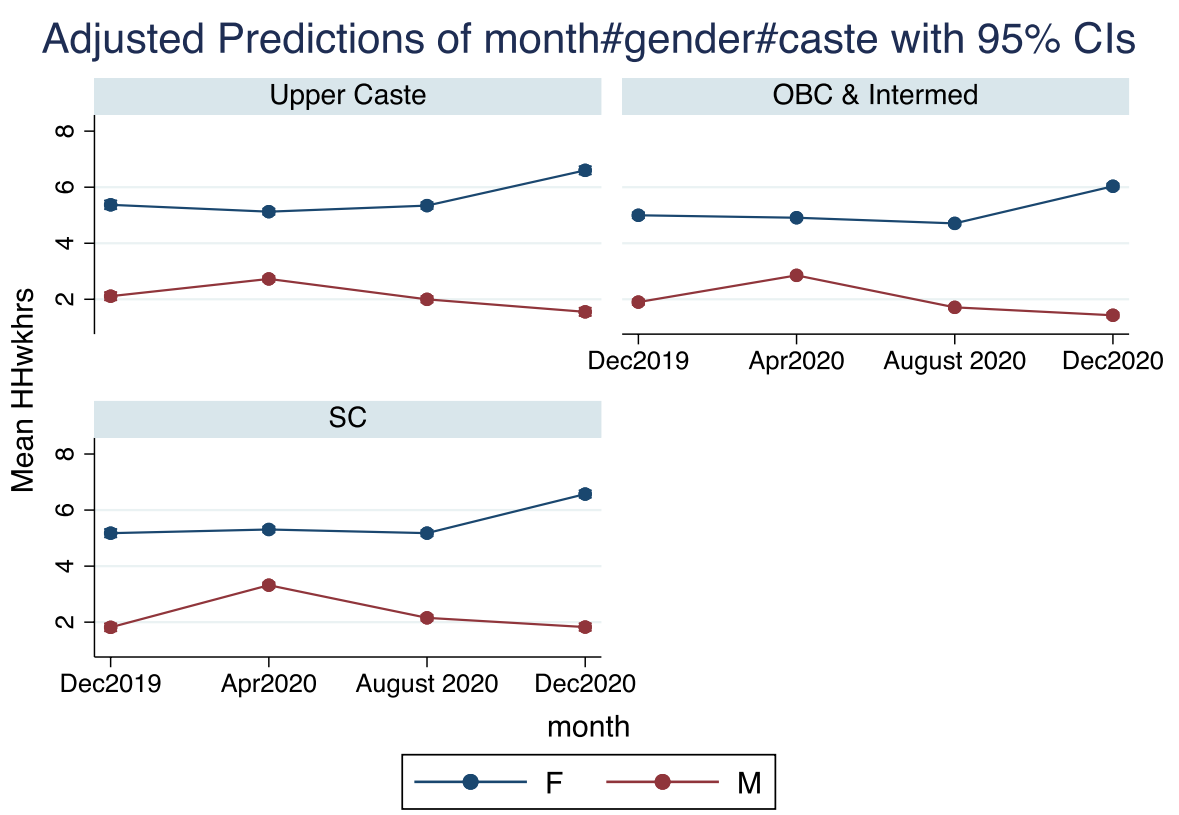

Fig. 10 Average hours spent on housework, by caste \& gender

\section{Unpaid domestic work and leisure}

The large demand-side constraint to women's participation in economic activity is the (non-) availability of suitable jobs. There is an important supply side constraint as well. South Asia (India and Pakistan in particular) and MENA (Middle East and North Africa) regions have among the most unequal gender norms in terms of sharing of household chores and domestic work, including care work. While these regions are at one end of the spectrum, women everywhere spend more time doing household chores compared men. The social norm of women being primarily responsible for housework is one of key constraints to their being able to access paid work from the supply side (Deshpande \& Kabeer, 2019).

A question actively being investigated in diverse parts of the world in the context of this massive exogenous shock in the form of pandemic is this: did the lockdown, which forced everyone to stay at home, and the need for social distancing which has resulted in the widespread adoption of WFH, shift the sharing of domestic work towards greater gender equality?

Since the pandemic is still ongoing, and countries are expected to go in and out of lockdowns till a sufficiently large number of people are vaccinated, there cannot be a definitive answer to this question until we emerge out of the pandemic decisively and have data covering the entire period. However, an analysis of the early evidence on this issue is both pertinent and interesting.

The CPHS data has included a question on "time spent on domestic work" in half-hour increments, starting with zero hours, since Wave 18 (September-December 2019). My previous estimates (Deshpande, 2020b), comparing gender gaps in 


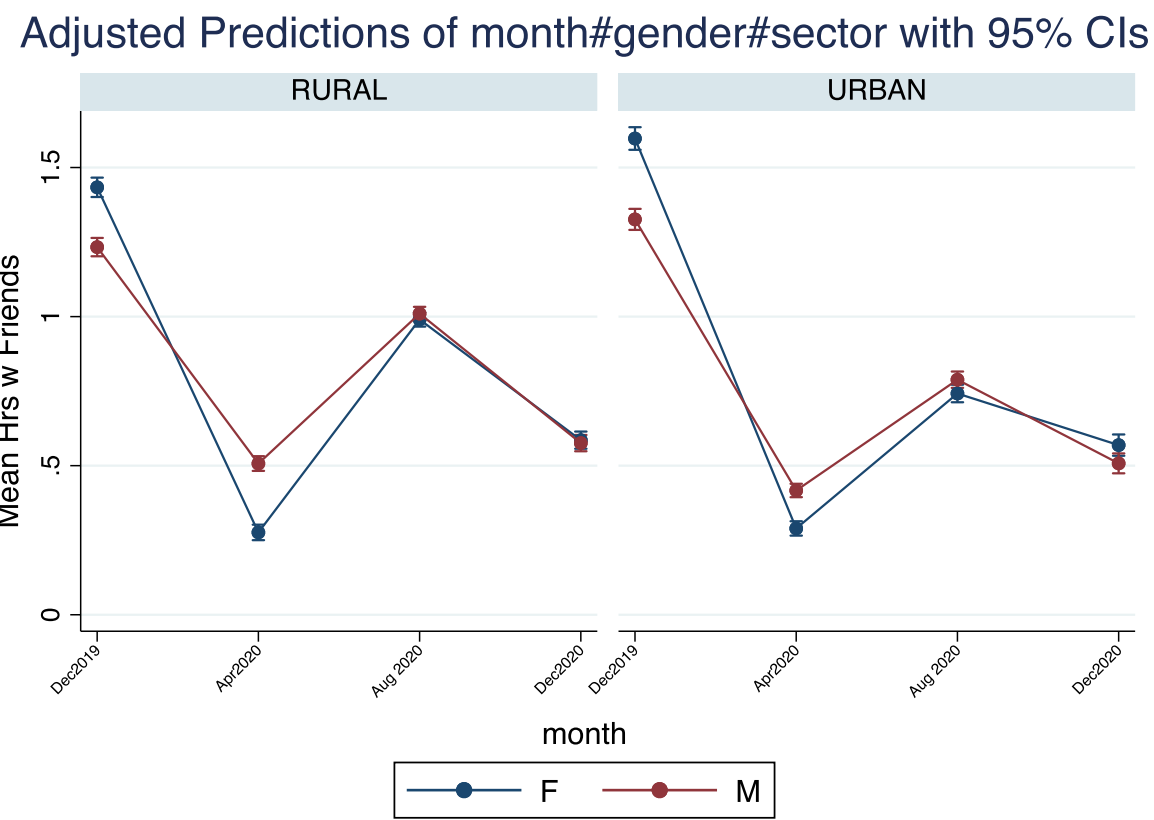

Fig. 11 Average hours spent with friends, by gender and sector, India

self-reported time spent on domestic work by men and women, revealed a decline in the average gender gap in time spent on housework, due to an increase in male hours men in the lockdown month of April 2020, compared to December 2019. the period of strict lockdown was marked by an absence of domestic helpers, integral to the lifestyles of a large number of Indian families. Anecdotal accounts suggest that men stepped up their contributions to housework in this extraordinary situation. Did the pattern persist with unlockdown as domestic helpers returned to work, and men returned to their paid jobs?

Figure 9 presents the marginal effects of gender on the predicted mean housework hours from ANOVA estimates. We see that by August 2020, men's time spent on housework had declined from the April high. Thus, the April spike in men's hours spent on domestic chores was an anomaly. By December 2020, there was a clear increase in the gender division of domestic chores. Women's hours spent on domestic chores have increased sharply and significantly above the pre-pandemic average, whereas men's hours have declined.

Figure 10 shows the gender differences in time spent on housework by caste. We see that the April spike in male hours on domestic work was driven to the largest extent by SC or Dalit men's increase, followed by OBCs. UC men registered the smallest increase. However, the increase in female hours between August and December 2020 is seen across all the caste groups. 
Table 2 FE and dynamic panel data models for lockdown panel

\begin{tabular}{lll}
\hline & $(1)$ & $(2)$ \\
& FE & Lagged emp \\
\hline Female & $-0.242^{* * *}(-3.64)$ & $-0.488^{* * *}(-28.84)$ \\
Aug2019 & $-0.00494(-0.50)$ & $0()$. \\
Dec2019 & $0.00170(0.24)$ & $0.00763(1.15)$ \\
Apr2020 & $-0.217^{* * *}(-8.44)$ & $-0.221^{* * *}(-4.83)$ \\
August 2020 & $-0.0204^{*}(-2.22)$ & $0.108^{* * *}(9.85)$ \\
Dec2020 & $-0.0227^{*}(-2.21)$ & $-0.0128(-1.64)$ \\
Female $\times$ Aug2019 & $0.00332(0.34)$ & \\
Female $\times$ Dec2019 & $-0.00191(-0.23)$ & $-0.00233(-0.33)$ \\
Female $\times$ Apr2020 & $0.196^{* * *}(7.17)$ & $0.210^{* * *}(5.38)$ \\
Female $\times$ August 2020 & $0.0157(1.07)$ & $-0.0897^{* * *}(-5.46)$ \\
Female $\times$ Dec2020 & $0.0115(0.86)$ & $0.00909(0.88)$ \\
Pre_emp & & $-0.237^{* * *}(-8.34)$ \\
Constant & & $1.017^{* * *}(26.55)$ \\
Observations & $0.512^{* * *}(16.26)$ & 76190 \\
\hline
\end{tabular}

The dependent variable is a dummy for being employed in period $t$. Column 1 shows the event study estimates arising from estimating Eq. (1) and column 2 from estimating Eq. (3) on the Lockdown Panel. The omitted month is April 2019 for Column 1, omitted gender is male. For Column 2, the omitted month is August 2019. The first month, April 2019, drops out because of the inclusion of lags. $t$ statistics in parentheses

${ }^{*} p<0.05,{ }^{* *} p<0.01,{ }^{* * *} p<0.001$

\subsection{Time spent with friends}

I examine another dimension of time allocation, time spent with friends. This is an important indicator, as it not only signifies leisure but also the possibility of de-stressing with someone outside the family, very important for emotional well-being. Figure 11 presents the marginal effects of gender on the predicted mean hours spent with friends, separately for rural and urban areas, from ANOVA estimates on the lockdown panel. We see that time spent with friends went down significantly in April for both men and women, but relatively more for women. Thus, in addition to the pressure of decreased employment, women had to bear the brunt of less time with their friends.

There was a brief recovery in time spent with friends for both men and women in rural as well as urban sectors. However, the time spent with friends in August 2020 was far lower than the pre-pandemic average. The recovery in urban areas was lower than that for rural areas. But the period between August and December 2020, which was also a period of declining employment, registered a decline in hours spent with friends, for both men and women, in rural and urban areas. 
The other noticeable feature is that while women spent more time with friends than men in the pre-pandemic period, in the post pandemic period, the relative position has reversed. By December 2020, the gender gap appears to have closed. This decline in hours spent with friends does not bode well for emotional well-being and could contribute to stress, anxiety and feeling of isolation.

\section{Discussion and concluding comments}

The Covid-19 pandemic has often been described as a great leveller. In several countries, early evidence has shown that regardless of which sections of the population are more vulnerable to the disease, the impact of the lockdown and economic shutdown, which is the key pandemic control strategy everywhere, has been highly uneven, hitting the already vulnerable groups much harder than. In this sense, the pandemic has exposed the many fault lines that lay beneath the surface across the world.

India, home to a third of the world's population, is no exception to this global pattern. Using six waves of longitudinal national data for roughly 54,000 individuals, this paper presents estimates for differential effects of the lockdown as well as recovery on employment on men and women.

Due to the pre-existing significant and widening gender gaps in labour force participation rates and employment, the absolute number of men who lost employment was larger than the absolute number of women who lost employment in the first month of the lockdown. However, even though pre-lockdown employment was the strongest predictor of post-lockdown employment, its effect was different for men and women. Accounting for lagged employment, women are $9.5 \%$ points less likely than men to be employed in August 2020, compared to the pre-pandemic levels. By December 2020, the gender gaps in employment were back to the pre-pandemic levels, but this was due to a decline in male employment, rather than an increase in female employment.

\subsection{Time use}

India has amongst the most unequal gender division of household work globally. Time Use Surveys, conducted by the Central Statistical Organisation of the Ministry of Statistics and Programme Implementation, provide a reference point against which the CMIE data can be assessed, while we note that the data sources are not comparable. The previous NSS survey in 1998-1999 across six states in India was considered a pilot; the latest national survey is for 2019, i.e. after a gap of two decades. The statistics from these surveys are not comparable, but instructive. The 1998-1999 survey found that men spent significantly more time on income earning and personal care (including leisure) activities compared to women. However, women spend 10 times as much time on household work, including unpaid work on family enterprises, compared to men (Central Statistical Organisation, 1999). 
The main results from the nationwide 2019 survey indicate that consistent with labour force statistics, women spend significantly less time than men in "employment and related activities". However, consistent with other evidence of women's involvement in unpaid economic work, they spend more time in "production of goods for own final use" compared to men. In "unpaid domestic service", women's participation rate is roughly four times that of men, and they spend about three times more time compared to men. Women spend roughly twice the time in unpaid care work, compared to men. Prima facie, this indicates that the gender gap in unpaid domestic and care work might have reduced over the last two decades. However, we have to note that the 2019 survey is not comparable to the 1998-99 one. We need at least two comparable surveys in order to accurately gauge change over time.

In this paper, comparing hours spent on domestic work pre- and post-lockdown, I find that for both men and women, the gender gap in average hours spent on domestic work hours decreased in the first month of the lockdown. This was due to an increase in male hours on domestic work, which was the highest among Dalit men. However, by August 2020, the male hours had again dropped, but not to the prepandemic levels. If this shift persists or gets accentuated, it would indicate a clear shift in gender norms.

\subsection{What does history tell us?}

Severe shocks can shift social norms defining gendered labour force patterns, which in turn could have an impact on the gendered division of domestic chores. For instance, the years after World War II resulted in a rise in female labour force participation in OECD countries (Long, 1958). This was also a time when the division of domestic chores shifted towards greater equality.

Specifically in the context of this pandemic, Alon et al. (2020) find that beyond the immediate crisis, work norms that normalize work from home as well as the norms of fathers participating in childcare might "erode erode social norms that currently lead to a lopsided distribution of the division of labor in house work and child care". For India, we would need to examine the evidence over a longer time period, as such changes unfold slowly over several years; a month-long lockdown is certainly no proof of the magnitude and persistence of shifts.

Sabarwal et al. (2010) discuss the first and second-order effects of the 2008 financial crisis. They find that the loss of employment for women already in the labour force -the first-order effect-depended on the sector of employment. However, economic crises can lead women outside the labour force to enter the workforce ("added worker effect") in response to declining family incomes. The evidence presented above shows an adverse first-order effect on women of the lockdown. The analysis presented above, with data till August 2020, does not reveal the positive second-order effect.

While women have suffered disproportionately more job losses, risky, hazardous and stigmatized jobs are exclusively their preserve. All frontline health workers, the trinity that forms the backbone of the primary healthcare system-ASHA (Accredited Social Health Activists), ANM (auxilliary nurse and midwife) and Anganwadi 
workers (the ICDS or Integrated Child Development Scheme workers) are women. Thus, for a very large number of women, the choice seems to be between unemployment and jobs that put them at risk of disease and infection and make them targets of vicious stigma.

Pandemics have implications for women's and children's health outcomes which, in addition to being important in themselves, have implications for women's ability to participate in paid work. For instance, school closures for prolonged periods, combined with the fact that women bear a disproportionate brunt of child-rearing responsibility, would negatively impact women's labour force participation. Minardi et al. (2020) examine evidence from earlier epidemics (Ebola and H1N1) and outline the multiple negative costs of school closures: lack of school meals which are a vital source of nutrition especially for disadvantaged children; disruption of education can increase the risk of child labour, early marriage, teen pregnancies and gendered sexual assaults.

Thus, lessons from earlier disruptions (wars or pandemics) point towards both negative and positive effects on women's ability to participate in paid work, as well as their role as sole providers of unpaid care work. For the Indian case, evidence so far seems to indicate the presence of most of the negative effects (lower employment, greater burden of domestic work and less time for leisure), but none of the positive effects.

India's economy "suffered even more than most" as a result of the first lockdown (The Economist, 2020). India's growth rate has been faltering over the last 6 years, decelerating each year since 2016, to reach $3.1 \%$ in the first quarter of 2020 (January-March), just before the Covid-19 pandemic hit India. in the June 2020 quarter, India's GDP contracted by $24 \%$, making it the worst performer among its peers. This has led to expectations of a large contraction over 2020, if not for longer. ${ }^{15}$

The early recovery in employment as the economy unlocked had already started to falter before India was hit by the second wave. With the second wave underway at the time of writing, which has been far deadlier than the first wave in terms of the ferocity of the disease, the country has gone into another prolonged period of lockdown. CMIE data suggest a sharp increase in unemployment, which is now in double digits. ${ }^{16}$ Thus, India's employment/unemployment challenge continues massive. To create and sustain a momentum in employment generation in the coming months, we need to see strong policies to provide employment and boost demand, in the absence of which job losses might mount, worsening the employment crisis. The results of this paper indicate that in addition to overall unemployment, pre-existing inequalities along gender lines are likely to get reinforced, unless the specific contours of disadvantage are recognised and addressed.

\footnotetext{
15 https://www.livemint.com/news/india/gdp-contraction-sets-india-behind-em-peers-11600760017416. html.

16 https://www.cmie.com/kommon/bin/sr.php?kall=warticle\&dt=2021-05-24\%2011:01:18\&msec=696.
} 
Acknowledgements Special thanks to Vidhya Soundararajan, Rajesh Ramachandran and Prachi Singh for excellent comments on earlier versions. This version updates and replaces two earlier working papers, which were presented at the at the SERI workshop on "Covid-19 and the Indian Economy" in September, 2020; the First Consumer Pyramids Research Seminar at CMIE; ASSA/IAFFE panel on "Women and Work: Macro Policies, Shocks and the Gendered Nature of Work" in January 2021; ISLE-ILO-IHD virtual Conference on "Implications of the Covid-19 Crisis for Labour and Employment in India: Impact, Strategies and Perspectives"; and at the weekly seminar of the Institute for Fiscal Studies, London. Thanks are due to the participants, especially Nomaan Majid, Alison Andrew, Britta Augsburg, Sonya Krutikova, Antonella Bancalari and Anne Brockmeyer for excellent comments; to Mahesh Vyas and Kaushik Krishnan of the Centre for Monitoring Indian Economy for clarifications related to data, and to Rukmini S. for her insightful questions. The usual disclaimer applies.

Funding This paper did not use any external funding. I used secondary data available at my institution.

\section{Declarations}

Conflict of interest (financial or non-financial) The author declare that they have no conflict of interest.

Informed consent if the research involved human participants Not applicable.

Statement on welfare of animals if the research involved animals Not applicable.

\section{References}

Alon, T., Doepke, M., Olmstead-Rumsey, J., \& Tertilt, M. (2020). The impact of covid on gender equality. NBER Working Paper No. 26947.

Andrew, A., Cattan, S., Costa Dias, M., Fuquharson, C., Kraftman, L., Krutikova, S., Phimister, A., \& Sevialla, A. (2020). The gendered division of paid and domestic work under lockdown. IZA Discussion Paper No. 13500, July.

Angrist, J. D., \& Pischke, J. S. (2009). Mostly Harmless Econometrics: An Empiricist's Companion. Princeton University Press.

Central Statistical Organisation (CSO). (1999). Report of the Time Use Survey, Ministry of Statistics and Programme Implementation, Government of India. http://www.mospi.gov.in/sites/default/files/publi cation_reports/Report\%20o\%20the\%20Time\%20Use\%20Survey-Final.pdf. Accessed Sept 2020.

Chiplunkar, G., Kelley, E., \& Lane, G. (2020). "Which Jobs are lost during a lockdown? Evidence from vacancy postings in India" (August 03, 2020). Darden Business School Working Paper No. 3659916, Available at SSRN: https://ssrn.com/abstract=3659916 or https://doi.org/10.2139/ssrn.3659916. Accessed Sept 2020.

Desai, S., Neerad, D., \& Santanu, P. (2020). COVID-19: Employment decline and recovery. In: Presentation at Ashoka University Economics Department Seminar Series, October 7, 2020.

Deshpande, A., \& Ramachandran, R. (2020). Is Covid-19 “The Great Leveler”? The Critical Role of Social Identity in Lockdown-induced Job Losses. GLO Discussion Paper No. 622.

Deshpande, A. (2020a). What does work from home mean for women? Economic and Political Weekly, $55(21), 23$.

Deshpande, A. (2020b). The Covid-19 pandemic and lockdown: First order effects on gender gaps in employment and domestic time use in India. GLO Discussion Paper, No. 607, Global Labor Organization (GLO), Essen. This version available at: http://hdl.handle.net/10419/222416.

Deshpande, A., \& Kabeer, N. (2019). (In)Visibility, care and cultural barriers: The size and shape of women's work in India. Working Papers 10, Ashoka University, Department of Economics.

Farre, L., Yarine, F., Libertad, G., \& Jennifer, G. (2020). How the COVID-19 lockdown affected gender inequality in paid and unpaid work in Spain. IZA Discussion Paper No. 13434, July

Fenske, J., Gupta, B., \& Yuang, S. (2020). Demographic shocks and women's labor market participation: Evidence from the 1918 influenza pandemic in India (p. 1286). No: Warwick Economics Research Papers. 
Ilkkaracan, I., \& Emel, M. (2020). Transformation in the gender imbalances in paid and unpaid work under the pandemic: Findings from a pandemic time-use survey in Turkey. Feminist Economics (forthcoming in)

Kesar, S., Rosa, A., Rahul, L., Paaritosh, N., \& Amit, B. (2020). Pandemic, informality, and vulnerability: Impact of COVID-19 on livelihoods in India. Centre for Sustainable Employment Working Paper, 2020-01, Azim Premji University, https://cse.azimpremjiuniversity.edu.in/wp-content/uploads/2020/06/ Kesar_et_al_Pandemic_Informality_Vulnerability.pdf. Accessed Sept 2020.

Long, C. D. (1958). The labor force under changing income and employment. http://econpapers.repec.org/ bookchap/nbrnberbk/long58-1.htm. Accessed Sept 2020.

Minardi, A. L., Susannah, H., \& Lee, C. (2020). Containing the epidemic: Should schools close for coronavirus? Centre for Global Development, February 28 https://www.cgdev.org/blog/containing-epidemicshould-schools-close-coronavirus. Accessed Sept 2020.

Sabarwal, S., Nistha, S., Mayra, B. (2010). How do women weather economic Shocks? A review of the evidence. Policy Research Working Paper No. 5496, The World Bank, December.

The Economist. (2020). "India's Economy has suffered even more than most", May 23, 2020.

Publisher's Note Springer Nature remains neutral with regard to jurisdictional claims in published maps and institutional affiliations. 